\title{
Advances in the study of demoralization: An overview
}

\author{
John M. de Figueiredo, MD, ScD \\ Department of Psychiatry. \\ Yale University School of Medicine \\ USA
}

Demoralization is the clinical presentation of many, if not all, individuals who seek psychotherapy, many patients with medical illnesses ("giving up-given up complex"), patients in the emergency departments ("crisis") and even patients with chronic mental illness ("social breakdown syndrome"). This unifying clinical construct was introduced in the psychiatric literature by Jerome D. Frank in his 1961 book Persuasion and Healing. By studying hundreds of patients with standard scientific methods, he demonstrated that successful psychotherapy worked by correcting assumptions that provoked demoralization and helping the patients restore their sense of mastery of their situations ${ }^{1-5}$.

In this issue several studies are brought together, expanding our knowledge of demoralization. Rafanelli et al. present a cluster analysis that identifies sub-types of demoralization in a large sample of medically ill patients. Kohn demonstrates that demoralization is a risk factor for post-traumatic stress disorder following a disaster. Briggs describes how the social and cultural context plays a crucial role in determining the degree of demoralization in refugees and immigrants.

Ultimately demoralization has to do with the life story of the patient. Frank reports how medical students rotating through Psychiatry can learn to recognize and relieve demoralization in patients by eliciting their life stories. Griffith explains how existential inquiry as a form of brief psychotherapy can counter demoralization by strengthening resilience.

Alarcon discusses the ambiguity faced when attempting to find the appropriate place for demoralization in our clinical reasoning: is demoralization a mental disorder, a homeostatic response to a stressful situation, or a combination of both? An attempt was made to clarify the position of demoralization in the spectrum of psychopathology by proposing that it involves two components, distress and subjective incompetence. As the stressful situation increases in duration or severity, some people with subjective incompetence experience helplessness, and some with helplessness become hopeless, and, at times, suicidal ${ }^{6}$. 
How can demoralization be distinguished from depression? A conceptualization of motivation as a vector, with a magnitude and a direction, may be helpful in establishing this distinction. Typically, a depressed individual knows what needs to be done to get out of the predicament, but lacks the magnitude of motivation to translate the knowledge into planned behavior. By contrast, a person who is demoralized is more than willing to end the distress but lacks the cognitive map to define the direction of future behavior ${ }^{7}$.

Together, these articles stimulate our thinking about an important clinical construct that emerges at the boundaries between person and environment, past and future, "normal" and "abnormal".

\section{References}

1. Engel GL. A psychological setting of somatic disease: the "giving up-given up complex". Proc R Soc Med 1967; 60: 553-555.

2. Engel GL. A life setting conducive to illness, the giving up-given up complex. Bull Menninger Clin 1968; 32: 355-365.

3. Caplan G. Principles of Preventive Psychiatry. New York: Basic Books; 1964.

4. Gruenberg EM. The social breakdown syndrome and its prevention. In: Caplan G, ed. American Handbook of Psychiatry. New York: Basic Books; 1974. p. 697-711.

5. Frank JD, Frank JB. Persuasion and Healing: A Comparative Study of Psychotherapy. $3^{\text {rd }}$ ed. Baltimore: The Johns Hopkins University Press; 1991.

6. de Figueiredo JM, Frank JD. Subjective incompetence, the clinical hallmark of demoralization. Compr Psychiatry 1982; 23(4): 353-363.

7. de Figueiredo JM. Depression and demoralization: phenomenological differences and research perspectives. Compr Psychiatry 1993; 34(5): 308-311.

Author for correspondence:

John M. de Figueiredo, MD, ScD

P.O. Box 573

Cheshire, CT 06410-0573

USA

Tel.: 2032729628

Fax: 2032725124

E-mail: johndefig@sbcglobal.net 